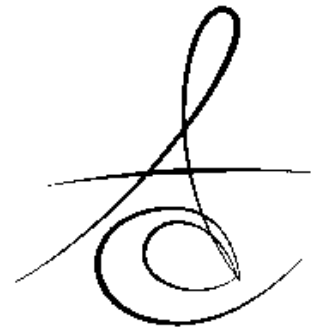

\title{
THE INDICATIONS FOR DENTAL VOLUMETRIC TOMOGRAPHY IN A TURKISH POPULATION SAMPLE
}

\author{
BİR TÜRK ÖRNEKLEM GRUBUNDA DENTAL VOLÜMETRİK TOMOGRAFİ \\ ENDİKASYONLARI
}

Yrd. Doç. Dr. Elif Tarım ERTAŞ*

Dt. Fahrettin KALABALIK*

\author{
Makale Kodu/Article code: 1378 \\ Makale Gönderilme tarihi: 01.11 .2013 \\ Kabul Tarihi: 07.01.2014
}

\section{ÖZET}

Amaç: Bu çalışmanın amacı; İzmir Kâtip Çelebi Üniversitesi, Diş Hekimliği Fakültesi'ndeki diş hekimlerinin dental volümetrik tomografi isteme nedenleri ve bu isteklerin bölüm, yaş ve cinsiyete göre dağılımlarının incelenmesidir.

Gereç ve Yöntem: Bu çalışmada, Ekim 2012-Ekim 2013 tarihleri arasında İzmir Katip Çelebi Üniversitesi, Diş Hekimliği Fakültesi Ağız, Diş ve Çene Radyolojisi Kliniğinde dental volümetrik tomografi(NewTom 5G, $\mathrm{QR}$, Verona, Italy) çekilmiş olan, toplam 470 hastanın bilgileri retrospektif olarak tarandı.

Bulgular: 243'ü kadın, 227'si erkek toplam 470 hastanın yaşlarının 6-73 arasında değiştiği ve ortalamasının 32,56 yıl olduğu belirlendi. En fazla isteğin $(\% 32,13)$ gömülü dişlerin değerlendirilmesi amacıyla yapıldığı saptandı. Tümör ve kist gibi patolojilerin değerlendirilmesi (\%23,62), implant planması $(\% 21,49)$, ortodontik amaçı istekler ve sinüs patolojilerinin değerlendirilmesi de başlıca diğer istek nedenleri olarak saptandı.

Sonuç: DVT klinik pratikte iki boyutlu radyografilerin sınırlı kaldığı pek çok vakada klinisyenler için vazgeçilmez bir teşhis aracı haline gelmiştir.

Anahtar Kelimeler: dental volümetrik tomografi, endikasyon, radyografi

\section{ABSTRACT}

Aim: The aim of this study was to investigate the indications of dental volumetric tomography prescriptions performed in İzmir Kâtip Çelebi University, Faculty of Dentistry and to examine the age and gender distribution of the patients.

Material and Method: In this study, 470 dental volumetric tomography data (NewTom 5G, $\mathrm{QR}$, Verona, Italy) obtained from patients who attended to İzmir Katip Çelebi University, Faculty of Dentistry for their dental problems between October 2012 and October 2013 were retrospectively evaluated.

Results: Out of 470 patients, 243 were female and 227 were male, whose ages ranged from 6-73 years $($ mean $=32.56)$. The major indications for dental volumetric tomography were for the evaluation of the impacted teeth with a percentage of $32.13 \%$, which was followed by the examination of bone pathologies like cysts and tumors (23.62 \%), the assessment for implant planning (21.49\%), and the evaluation of orthodontic anomalies and sinus pathologies respectively.

Conclusions: Dental volumetric tomography has become an indispensable diagnostic tool in clinical practice for many professions where two-dimensional radiography remains limited in many cases.

Key Words: Dental volumetric tomography, indication, radiography.

\section{GİRİŞ}

Diş hekimliğinde geleneksel radyografik görüntüleme araçları olan periapikal, panoramik, oklüzal ve sefalometrik vb. grafiler sadece iki boyutlu inceleme imkânı sağladığından; mandibular kanal, maksiler sinüsler ve TME gibi yapıların anatomisi ve patolojileri, kemik kalınlığı, lezyonların lokalizasyonu ve boyutu, kök kanal anatomisi hakkında sınırlı bilgiler sağlar. ${ }^{1}$ Ayrıca iki boyutlu görüntü veren bu yöntemlerde; çevre dokuların süperpozisyonu, magnifikasyon, görüntülerin distorsiyonu, perspektif problemleri gibi dezavantajlar da mevcuttur. ${ }^{2}$ İki

*İzmir Kâtip Çelebi Üniversitesi, Diş Hekimliği Fakültesi, Ağız Diş Ve Çene Radyolojisi Anabilim Dalı, 
boyutlu görüntü veren sistemlerdeki yetersizlik, araştırmacıları üç boyutlu görüntüleme teknikleri üzerinde çalışmalar yapmaya yönlendirmiştir. ${ }^{3}$

X-ışınlarının keşfinden sonra, radyolojideki en önemli gelişme olarak kabul edilen bilgisayarlı tomografi (BT), maksillofasiyal yapıların üç boyutlu olarak değerlendirilmesine de olanak sağlamıştır. ${ }^{1}$ BT'nin maliyetinin yüksek olması ve her merkezde bulunmaması, özellikle hastaların maruz kaldığı radyasyon miktarının yüksek olması, tarama ve görüntü işleme sırasında geçen sürenin uzun olması, küçük apikal ve alveoler lezyonların saptanması için çözünürlüğün yeterli olmaması gibi nedenlerden dolayı diş hekimliğinde kullanımı sınırı kalmıştır. ${ }^{4,5}$

Geleneksel BT'deki sorunların giderilmesi amacı ile konik ışınlı bilgisayarlı tomografi veya dental volumetrik tomografi (DVT) olarak adlandırılan görüntüleme sistemi geliştirilmiştir ve ticari olarak 2001 yllında (NewTom QR DVT 9000; Quantitative Radiology, Verona, İtalya) satışa sunulmuştur ${ }^{5,6}$. Bu sistem özellikle baş ve boyun uygulamalarında yoğun ilgi görmüştür. ${ }^{7,8}$

DVT, BT'ye göre birçok avantaja sahiptir. DVT'de $x$-ışını demeti sınırlandırılabildiğinden ve $x$ ışınları yalnızca görüntülenecek alana yönlendirildiğinden hastanın maruz kaldığı radyasyon dozu çok daha azdır. DVT'de voksellerin izotropik olmasından dolayı daha doğru ve hassas ölçümler yapılabilmektedir. Hızlı tarama süresi ve bu sürenin kısa olmasına bağlı olarak hareket artefaktları azalmaktadır. DVT'de geliştirilen artefakt azaltıcı yazılımsal algoritmalar sayesinde metal artefaktları önemli derece azalmış ve daha kaliteli görüntü oluşturma imkânı ortaya çıkmışıı. ${ }^{9}$

DVT diş hekimliğinde; implant planlama, patolojilerin boyut ve lokalizasyonun değerlendirilmesi, kök kanal morfolojileri ve köklerin çevre dokular ile olan komşuluklarının incelenmesi, bu yapılara ait patolojilerin belirlenmesi, gömülü dişler, TME morfoloji ve patolojileri, paranazal sinüslerin değerlendirilmesi, hava yolu analizi, damak yarığı olan hastalarda yarık sınırlarının belirlenmesi gibi birçok alanda kullanılmaktadır. 2,8,10

Bu çalışmada; İzmir Kâtip Çelebi Üniversitesi, Diş Hekimliği Fakültesi Ağız, Diş ve Çene Radyolojisi kliniğinde çekilmiş olan DVT'lerin istek nedenleri ve bu isteklerin bölüm, yaş ve cinsiyete göre dağlımlarının incelenmesi amaçlanmıştır.

\section{GEREÇ VE YÖNTEM}

İzmir Kâtip Çelebi Üniversitesi, Diş Hekimliği Fakültesi, Ağız Diş ve Çene Radyolojisi arşivinde Ekim 2012 ile Ekim 2013 tarihleri arasında çekilen DVT görüntüleri retrospektif olarak incelendi. Çalışmaya NewTom 5G DVT cihazı (QR, Verona, İtalya) $(k V=110$ ve $m A=1-20$ ) ile görüntüleri elde edilen, yaşları 6 ile 73 arasında değişen toplam 470 hastaya (243 kadın, 227 erkek) ait görüntü dahil edildi. Hastaların yaşı, cinsiyeti, DVT istenme nedeni ve DVT talep eden bölümler kaydedildi. Bölümlerin DVT isteme oranları, DVT'nin en fazla istendiği durumlar ve DVT istenen hastaların ortalama yaşları hesaplandı.

\section{BULGULAR}

Çalışmaya dâhil edilen 243'ü kadın, 227'si erkek toplam 470 hastanın yaşlarının 6 ile 73 arasında değiştiği (ortalama 32,56 yıl) belirlendi. Kadınlar için yaş ortalaması 32,42 , erkekler için 32,71 olarak hesaplandı. Kadın ve erkek hastalar için yapılmış olan DVT istek nedenleri birbirine paraleldi. 6-18 yaş aralığındaki hastalarda çoğunlukla, gömük dişlerin özellikle de gömük kanin dişlerin sürme yönünün belirlenmesi ve komşu dişlerde meydana getirdiği rezorpsiyonların değerlendirilmesi amacıyla DVT istendiği ortaya kondu. 18-30 yaş aralı̆ındaki hastalardan en fazla gömük yirmi yaş dişlerin değerlendirilmesi için DVT istendiği belirlendi. 30 yaş üzerindeki hastalardan ise en sık implant planlama amacıyla DVT talebi olduğu saptandı. Ayrıca bu yaş grubunda kemik içerisindeki tümor, kist gibi lezyonların değerlendirilmesi için yapılmış olan istekler de oldukça fazlaydı. Tablo 1'de DVT çekilmiş hastaların yaş ve cinsiyete göre dağılımları gösterilmektedir.

Tablo 1. DVT çekilmiş hastaların yaş ve cinsiyete göre dağılımları.

\begin{tabular}{llll}
\hline & Kadın & Erkek & Toplam \\
\cline { 2 - 4 } Hasta sayısı & $243(\% 51,7)$ & $227(\% 48,3)$ & 470 \\
Yaş ortalaması & 32,42 & 32,71 & 32,56 \\
\hline
\end{tabular}


Kliniğimizde çekilen tüm DVT'lerin istenilen kliniklere göre dağılımı Tablo 2'de yer almaktadır. Son 1 yıl içerisinde en fazla DVT isteği ile hasta yönlendiren bölümler arasında ilk sırada Ağız Diş ve Çene Cerrahisi Kliniği yer almaktaydı.

İncelenen tüm veriler arasında DVT endikasyon nedenleri sıralandığında; gömük dişler ilk sırayı almaktaydı. Tablo 3'te kliniğimizde çekilen tüm DVT'lerin endikasyon nedenlerine göre dağılımı yer almaktadır.

Tablo 2. Tüm DVT'lerin istenilen kliniklere göre dağılımı.

\begin{tabular}{|c|c|c|c|c|c|}
\hline \multirow[b]{2}{*}{ Bölüm } & \multicolumn{3}{|c|}{ İstek Sayısı } & \multirow[b]{2}{*}{ Yaş ort. } & \multirow[b]{2}{*}{ Yüzdesi (\%) } \\
\hline & Kadın & Erkek & Toplam & & \\
\hline \multicolumn{6}{|l|}{ Ağız Diş Ve Çene } \\
\hline Cerrahisi & 106 & 110 & 216 & 39,26 & 45,96 \\
\hline Ortodonti & 64 & 38 & 102 & 14,54 & 21,70 \\
\hline \multicolumn{6}{|l|}{ Ağız Diş Ve Çene } \\
\hline Radyolojisi & 29 & 39 & 68 & 41,74 & 14,47 \\
\hline Endodonti & 23 & 15 & 38 & 32,5 & 8,09 \\
\hline Pedodonti & 10 & 16 & 26 & 10,5 & 5,53 \\
\hline Periodontoloji & 9 & 9 & 18 & 51,4 & 3,83 \\
\hline Protez & 2 & 0 & 2 & 45,5 & 0,43 \\
\hline Toplam & 243 & 227 & 470 & & 100 \\
\hline
\end{tabular}

Tablo 3. DVT'lerin endikasyon nedenlerine göre dağılımı.

\begin{tabular}{lll}
\hline & İstek Sayısı & Yüzdesi (\%) \\
\cline { 2 - 3 } Gömük Diş & 151 & 32,13 \\
Lezyon & 111 & 23,62 \\
İmplant Planlama & 101 & 21,49 \\
Ortodontik Amaçlı & 15 & 3,19 \\
Sinüs Değerlendirme & 15 & 3,19 \\
Damak Yarığı & 9 & 1,91 \\
Diğer & 68 & 14,47 \\
\hline Toplam & 470 & 100 \\
\hline
\end{tabular}

İstek yapan bölümler göz önüne alınarak değerlendirildiğinde, Ağız Diş ve Çene Cerrahisi Anabilim Dalı tarafından yapılan istekler arasında ilk sırayı; implant cerrahisi öncesi kemikteki uygun alanların seçimi, doğru kemik ölçümlerinin yapılması, implant yerleştirilecek alana komşu anatomik yapıların değerlendirilmesi, yerleştirilecek implant sayı ve boyutlarının belirlenmesi amacıyla yapılan isteklerin aldığı görüldü. Gömülü dişlerin lokalizasyonu, pozisyonu, komşu dişler ve anatomik yapılar ile olan ilişkilerinin değerlendirmesi amacıyla alınan DVT'lerin ikinci sırada yer aldığı saptandı. Gömülü dişler arasında sırası ile en çok yirmi yaş dişleri, kanin dişler ve premolar dişler görüntülendi. Bunun yanı sıra, kemik içerisindeki tümör ve kist gibi patolojilerin büyüklüğü, sınırları, komşu anatomik yapılarla ilişkilerinin ve anatomik malformasyonların değerlendirilmesi, TME ye ait kemik yapıların incelenmesi, paranazal sinüslerin, oro-antral ilişki ve çene yüz bölgesindeki fraktürlerin değerlendirilmesi bu bölüme ait diğer DVT istek nedenleri arasındaydı (Şekil 1).

Ortodonti Anabilim Dalı'nın DVT endikasyonları incelendiğinde; gömülü dişlerin sürme yönü, lokalizasyonu, komşu dişlerde rezorpsiyon oluşturup oluşturmadığının değerlendirilmesi ve anatomik yapılarla ilişkilerin değerlendirmesi amacıyla alınan DVT'lerin ilk sırada olduğu belirlendi. İncelenmesi için gönderilen gömülü dişler arasında ilk sırada gömülü kanin dişler ve sırası ile süpernümerer dişler ve premolar dişler gelmekteydi. Damak yarığı, alveol kemik değerlendirmesi, kök anomalileri, kondil anomalileri ve sefalometrik analizler bu bölümün diğer DVT istek nedenleri arasında sıralandı (Şekil 2).

Ağız Diş ve Çene Radyolojisi Anabilim Dalı tarafından yapılan DVT istekleri incelendiğinde, implant cerrahisi öncesi değerlendirmeler amacıyla alınan DVT'ler hariç diğer endikasyonlar Cerrahi kliniğinden gelen endikasyonlar ile oldukça paraleldi (Şekil 3).

Endodonti Anabilim Dalı en fazla apikal lezyonların değerlendirilmesi amacıyla DVT isteği yapmıştı. Kökte kırık ve çatlak şüphesi, internal ve eksternal rezorpsiyon, apeks incelemesi ve benzeri durumlar, bu bölümün diğer DVT istek nedenleri arasında sıralandı (Şekil 4).

Pedodonti Anabilim Dalı́nın DVT endikasyonları çekilen tüm DVT'lerin \% 5,53'ünü oluşturmaktaydı. Bu bölümün DVT istek nedenleri arasında ilk sırada sürme yönü, pozisyonu ve komşu dişlerde rezorpsiyon olup olmadığının belirlenmesi amacıyla gömülü diş vakaları yer aldı. Bunun yanı sıra; kemik içi kistik lezyonlar ve travma sonrası diş ve çevre dokularının kontrolü amacıyla yapılan istekler diğer endikasyonlar arasında yer aldı (Şekil 5). Çalışmaya dâhil edilen en genç hasta olan 6 yaşındaki çocuktan gömülü dişlerinin sürme yönünün değerlendirmesi amacıyla DVT isteği yapılmıştı. 
İncelenen tüm hasta verileri arasında Periodontoloji Anabilim Dalı tarafindan yapılan DVT istekleri sondan bir önceki sırada yer aldı. Periodontoloji kliniğinden; implant cerrahisi öncesi kemikteki uygun alanların seçimi, doğru ölçümlerinin yapılması, yerleştirilecek implant sayısı ve boyutlarının belirlenmesi, maksiler sinüsler ve inferior alveolar sinir gibi komşu anatomik yapıların değerlendirilmesi amacıyla DVT istenmişti (Şekil 6).
Protetik Diş Tedavisi Anabilim Dalı'ndan yönlendirilen 2 hastanın DVT çekim endikasyonu ortognatik cerrahi sonrası değerlendirme ve implant planlaması amacıyla konulmuştu.

Tüm kliniklerimiz arasında Diş Hastalıkları ve Tedavisi Anabilim Dalı'na ait DVT isteği yer almadı.

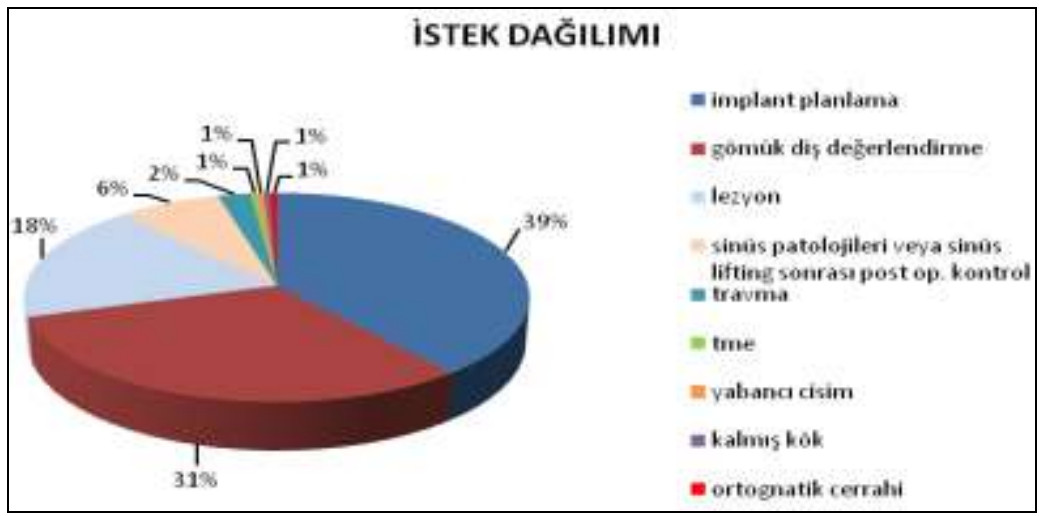

Grafik 1. Ağız Diş Ve Çene Cerrahisi Anabilim Dalı Tarafından Yapılan İstekler

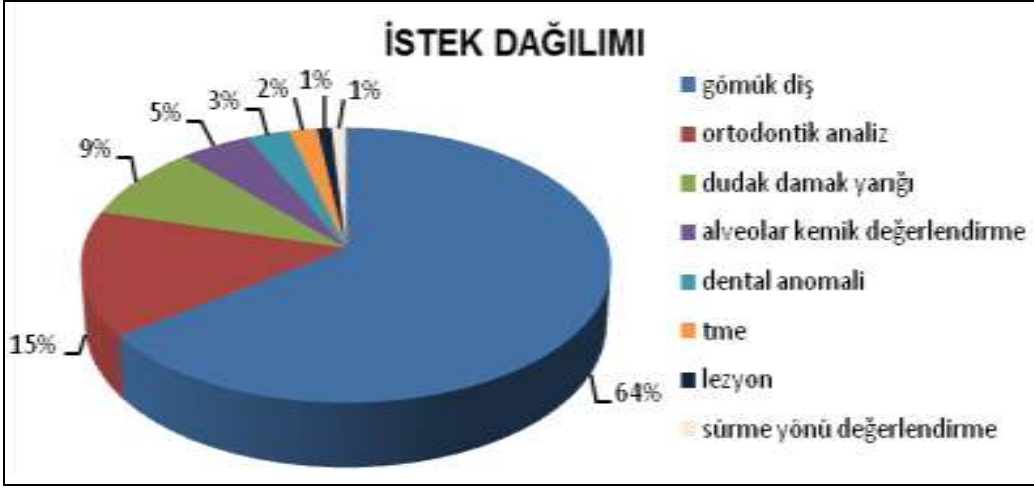

Grafik 2. Ortodonti Anabilim Dalı Tarafından Yapılan İstekler

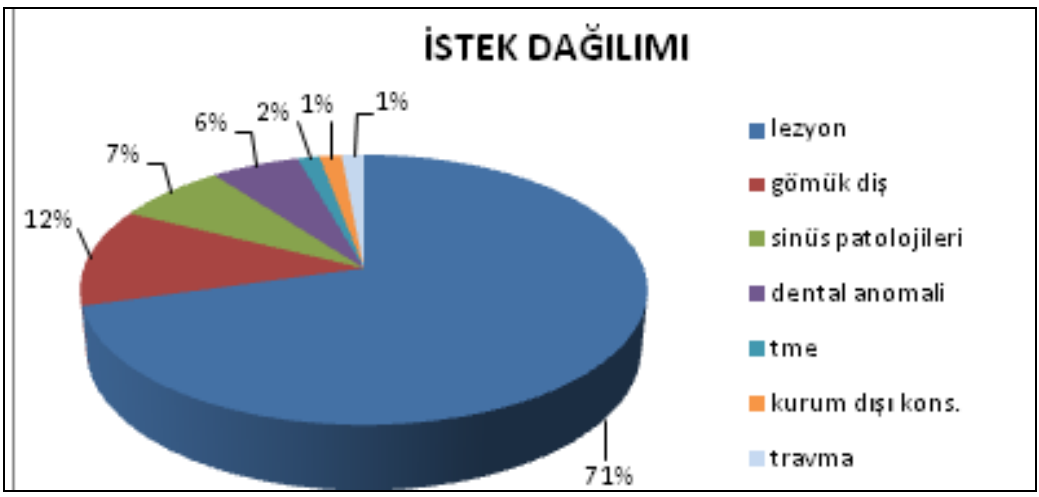

Grafik 3. Ağız Diş Ve Çene Radyolojisi Anabilim Dalı Tarafından Yapılan İstekler 


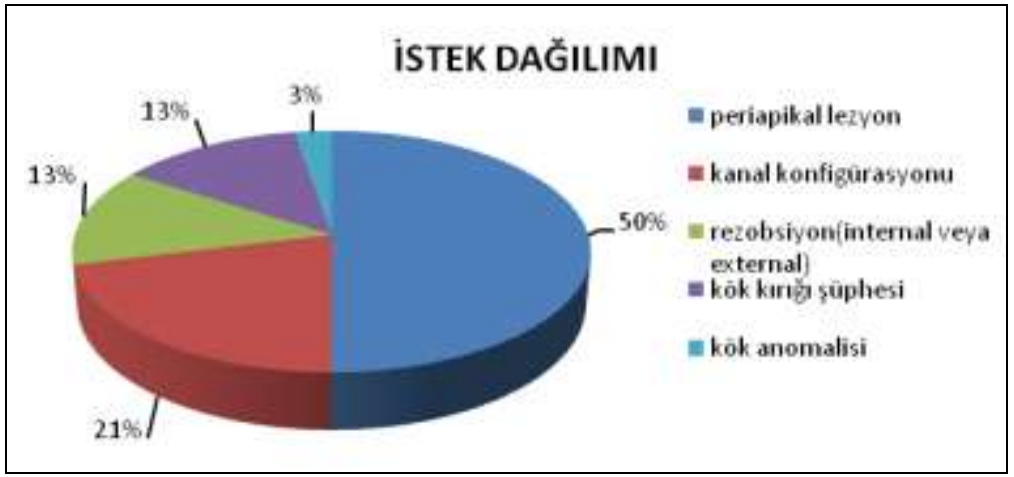

Grafik 4. Endodonti Anabilim Dalı Tarafından Yapılan İstekler

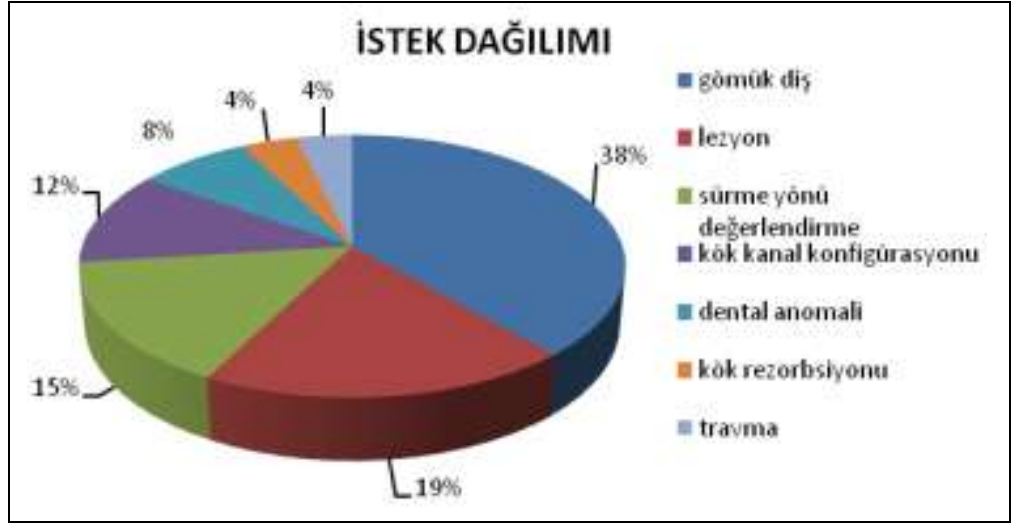

Grafik 5. Pedodonti Anabilim Dalı Tarafından Yapılan İstekler

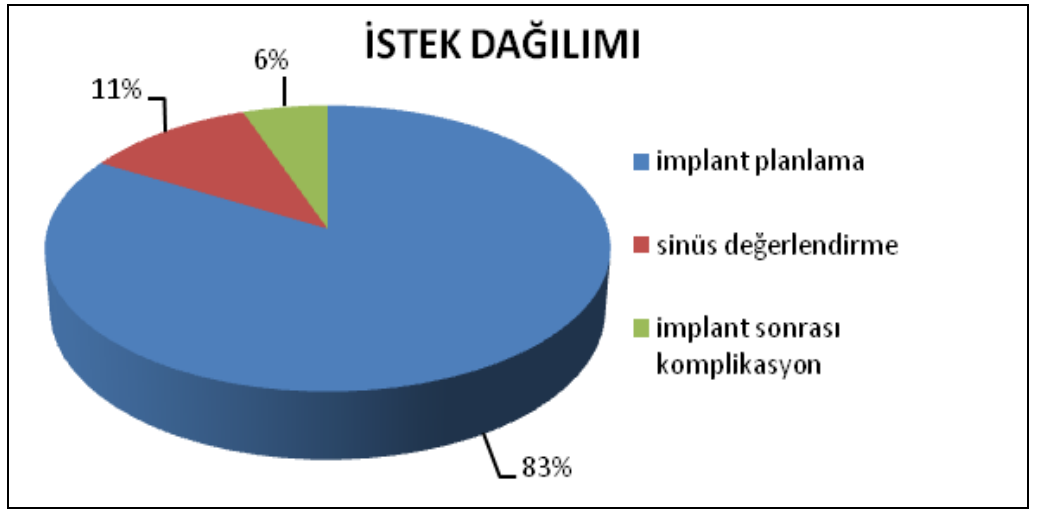

Grafik 6. Periodontoloji Anabilim Dalı Tarafından Yapılan İstekler 


\section{TARTIŞMA}

DVT sayesinde maksillofasiyal bölgeden; düşük doz radyasyon kullanılarak, yüksek çözünürlükte üç boyutlu görüntüler elde etme imkânı doğmuştur. Diş hekimliğinde iki boyutlu radyografilerin yeterli olmadığı birçok konuda DVT görüntülerine ihtiyaç duyulmaktadır. ${ }^{9}$

Çalışmamızda DVT istenme nedenleri ve bu isteklerin bölüm, yaş ve cinsiyete göre dağılımları incelenmiştir. Bulguları benzer çalışmalarla kıyaslayabilmek için yapılan literatür taramasında, çocuklardan ve genç erişkinlerden çekilmiş olan DVT'lerin istek nedenleri ve tüm hastalara göre dağıımını konu alan sadece bir adet çalışma

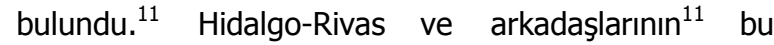
çalışmasında yaş ortalaması 13,1 olan 18 yaş altı DVT çekilmiş hastalar tüm çalışma grubunun \% 13,7'sini oluşturmuştu. Çocukların ve genç erişkinlerin dâhil edildiği bu çalışmada en fazla DVT çekilme nedeni gömük kanin dişlerinin incelenmesi ve komşu dişlerdeki rezorpsiyonların belirlenmesi olarak bildirilmiştir. ${ }^{11}$ Çalışmamızda 18 yaş altı gurubundaki hastaların yaş ortalaması, bu çalışma ile benzer $(13,1)$ bulunmuştur. Bununla birlikte, bizim çalışmamızda da aynı yaş grubundaki hastalarda en fazla gömülü kanin dişlerin değerlendirilmesi amacıyla DVT çekilmiştir.

Gömük dişler; komşu dişlerde kök rezorpsiyonlarına, fokal enfeksiyona, tümör ve kist gibi patolojilere, temporomandibular eklem şikayetlerine ve nevraljiform ağrılara neden olabilmektedir. ${ }^{1,5,12}$ Gömük dişlerin lokalizasyonunun ve komşu dişlerle ilişkilerinin belirlenmesi, rezorpsiyon varlığında komşu dişlerin değerlendirilmesi amacıyla iki boyutlu radyografiler (periapikal, panoramik, oklüzal ve sefalometrik radyografiler) ve üç boyutlu görüntüleme sistemleri kullanılmaktadır. ${ }^{13,14}$ Üç boyutlu sistemler süperpozisyonları engelleyerek 2 boyutlu görüntü veren radyografiler ile tam olarak izlenemeyen yapıları detaylı bir şekilde inceleme olanağı sağlar. ${ }^{15,16}$

Çalışmamızda gömülü dişlerin sürme yönü ve pozisyonunun, komşu dişlerde rezorpsiyona yol açıp açmadığının ve diş etrafındaki kistik değişiklerin değerlendirilmesi amacıyla, kanin dişlerinden çekilen DVT'ler tüm gömülü dişler için çekilen DVT'ler arasında ilk sırayı almaktadır (\% 41,06). Gömülü yirmi yaş dişlerinin mandibular kanal, maksiller sinüs ve komşu dişler ile ilişkilerini belirlemek amacıyla yapılan DVT isteklerini $(\% 29,14)$ gömülü süpernümere dişler için yapılan istekler izlemektedir (\% 14,57).

İmplant planlaması sırasında diş hekimi; implant yerleştirilecek bölge hakkında, kemik kalınlığı ve yapısı, bölgede yer alan ya da komşuluğunda bulunan sinirler, damarlar, nazal kavite, sinüs gibi anatomik yapılar hakkında bilgilere gereksinim duymaktadır ${ }^{17} \mathrm{Bu}$ amaçla, implant planlamasında iki boyutlu görüntü veren geleneksel dental radyografi sistemleri ve üç boyutlu görüntüleme sistemleri kullanılmaktadır. ${ }^{18}$ Geleneksel dental radyografilerin en önemli avantajı hastanın maruz kaldığı radyasyon dozunun düşük olmasıdır. ${ }^{19,20} \mathrm{Bu}$ radyografiler; diğer yapıların görüntüsü istenen bölge üzerine süperpozisyonu, görüntülerde genişleme ve daralma, çekim hataları ve pozisyon artefaktları gibi birçok dezavantaja sahiptir. ${ }^{18,21}$ Sarment ve arkadaşları ${ }^{22}$ ve Kramer ve arkadaşları ${ }^{23 \prime n ı n ~ y a p m ı s ̧ ~ o l d u k l a r ı ~}$ çalışmalarda, üç boyutlu görüntüleme sistemleri kullanılarak yapılan implant planlaması sonucunda yerleştirilen implantların, geleneksel dental radyografiler kullanılarak yerleştirilen implantlardan daha doğru ve uygun konumda yerleştirildiği ortaya konmuştur.

İmplant planlamasında kullanılan başlıca üç boyutlu görüntüleme teknikleri BT ve DVT dir. ${ }^{24-26}$ DVT'nin BT'ye göre daha küçük kesit kalınlığı ile görüntülerin elde edilmesine olanak sağlaması, daha kısa sürede, gerçek boyutta ve yüksek çözünürlükte görüntüler elde edilmesi, ${ }^{20,26}$ hastanın maruz kaldığı radyasyon miktarının da BT cihazlarından yaklaşık 1520 kat daha az olması gibi önemli üstünlükleri olduğu bilinmektedir. ${ }^{20,27-29}$ Cihazın tipine ve modeline göre değişmekle birlikte DVT'nin etkili dozu 52- $1025 \mu \mathrm{Sv}$ arasındadır; BT cihazlarında ise bu değer 860- 2100 $\mu$ Sv arasında değişmektedir. ${ }^{26,30}$ Ayrıca görüntülenen yapıların etrafında hayali gölgelerin oluşumu BT'nin diğer bir dezavantajıdır. ${ }^{19}$ Kobayashi ve arkadaşları ${ }^{31}$ DVT ve BT için hata payını hesaplamışlar ve hata payını DVT cihazları için $0.22 \mathrm{~mm}(\% 1,4)$ ve BT için $0.36 \mathrm{~mm}$ (\% 2,2) olarak belirtmişlerdir. Azari ve Nikzad $^{32}$, yaptıkları araştırmalarda farklı görüntüleme yöntemlerinin doğruluk ve distorsiyon derecesinin karşılaştırıldığını ve araştırıcıların panoramik görüntülerde \% 17, geleneksel tomografilerde \% 39, periapikal görüntülerde $\% 53$, ve $B T^{\prime}$ de $\% 95$ doğruluk elde ettiklerini belirtmişlerdir. 
Çalışmamızda implant planlama için istenilen DVT görüntüleri tüm isteklerin \% 25,19'unu oluşturmaktadır ve bu istekler Ağız Diş ve Çene Cerrahisi ve Periodontoloji klinikleri tarafından yapılmıştır.

Avrupa Osseoentegrasyon Birliği (European Association of Osseointegration- EAO), implant planlamasında kesitsel radyografik görüntülerinin temel görüntüler olduğunu vurgulamış ve postoperatif DVT çekimlerinin rutin bir protokol haline getirilmeden yalnızca sinir hasarı olduğunda ya da sinüs veya nazal kavitelerde postoperatif enfeksiyon durumlarında istenmesinin uygun olduğunu belirtmiştir. ${ }^{17}$ Çalışmamızda implant uygulaması sonrası sinir hasarı ve sinüs lifting uygulaması sonrasında greft materyalinin değerlendirilmesi amacıyla 8 adet DVT isteği bulunmaktadır.

Maksillofasiyal bölgedeki patolojik oluşumları görüntülemek amacıyla değişik yöntemler kullanımaktadır. Bununla birlikte, iki boyutlu görüntüleme araçları teknik özelliklerinden kaynaklanan yetersizlikler nedeniyle lezyonların lokalizasyonu, boyutu, sınırları ve çevre anatomik yapılarla ilişkisi hakkında yanlış değerlendirmeye neden olabilmektedir. DVT sayesinde, konvansiyonel radyografiler ile görüntülenemeyen lezyonların internal yapısı ve kesin lokalizasyonu ile ilgili üç boyutlu, ayrıntılı bilgiler elde etmek mümkündür. ${ }^{33-35}$ Çalışmamızda, çenelerdeki lezyonları değerlendirmek için istenilen DVT görüntüleri tüm isteklerin \% 22,8'ini oluşturmaktadır. Ağız Diş ve Çene Radyolojisi Anabilim Dalı teşhis ve lezyonların üç boyutlu olarak değerlendirmesi için en fazla DVT isteği yapan bölümdü. Cerrahi tedavinin planlamasında Ağız Diş ve Çene Cerrahisi bölümü, periapikal lezyonların değerlendirilmesi amacıyla Endodonti bölümü hasta yönlendiren diğer bölümlerdir.

DVT teknolojisi kraniyofasiyal kemik yapıların ve dişlerin, iki boyutlu radyografilerle elde edilemeyen, yüksek kontrastlı çok sayıda kesitsel ve sefalometrik görüntülerin elde edilmesini sağlar. 2,36,37 Çalışmamızda ortodontik amaçı DVT istekleri tüm isteklerin \% 3,19' u olarak bulunmuştur.

Paranazal sinüslerin radyografik muayenesinde geleneksel iki boyutlu radyografiler, BT ve DVT kullanılmaktadır. ${ }^{38}$ Sinüs radyografisinde kullanılan konvansiyonel radyografilerin; ideal hasta pozisyonunu sağlamada güçlük, diğer anatomik yapıların süperpozisyonu ve yumuşak ve sert doku patolojilerinin tespitindeki zorluklar gibi dezavantajları vardır. ${ }^{39}$
Maksillofasiyal bölgenin sert dokularını görüntülemek için tasarlanmış olan DVT, $\mathrm{BT}^{\prime}$ ye göre daha düşük doz ve daha az maliyet avantajına sahiptir. ${ }^{40}$ Çalışmamızda maksiller sinüs patolojilerinin ve maksiller sinüsteki yabancı cisimlerin görüntülenmesi amacıyla yapılmış olan DVT istekleri toplam isteklerin \% 3,19' unu oluşturmaktadır.

Son yıllarda DVT ile yapılan çalışmaların sayısında önemli oranda artış mevcuttur. DVT'nin maksillofasiyal bölgede kullanım sıklığı üzerine yapılacak benzer çalışmalar sayesinde, genel olarak bu üç boyutlu görüntüleme sisteminin en çok hangi durumlarda tercih edildiği, sağladığı avantajlar, diğer kullanım alanları ve limitasyonları hakkında bilgi elde etmek mümkün olacaktır.

\section{KAYNAKLAR}

1. Vandenberghe B, Jacobs R, Yang J. Diagnostic Validity (or Acuity) of 2d Ccd Versus 3d CbctImages for Assessing Periodontal Breakdown. Oral Surg Oral Med Oral Pathol Oral Radiol Endod 2007;104:395-401.

2. Scarfe WC, Farman AG. What Is Cone-Beam Ct and How Does It Work? Dent Clin North Am 2008;52:707-30, v.

3. Grőndahl HG, Huumonen S. Radiographic Manifestations of Periapical Inflammatory Lesions. Endod Topics . 2004;8:55-67.

4. Harorlı A, Akgül, H.M. , Dağistan, S. Diş Hekimliği Radyolojisi. 1 ed. Erzurum; 2006.324-5.

5. Güven $Y$, Aktören $O$, Gençay $K$. Dentomaksillofasiyal Bölge Görüntülemesinde Kullanılan Üç Boyutlu Bilgisayarlı Tomografi Sistemleri. 2008;15:159-64.

6. Miracle AC, Mukherji SK. Conebeam Ct of the Head and Neck, Part 2: Clinical Applications. AJNR Am J Neuroradiol 2009;30:1285-92.

7. Daly MJ, Siewerdsen JH, Moseley DJ, Jaffray DA, Irish JC. Intraoperative Cone-Beam $\mathrm{Ct}$ for Guidance of Head and Neck Surgery: Assessment of Dose and Image Quality Using a C-Arm Prototype. Med Phys 2006;33:3767-80.

8. Khoury A, Whyne CM, Daly M, Moseley D, Bootsma $\mathrm{G}$, Skrinskas $\mathrm{T}$, et al. Intraoperative Cone-Beam $\mathrm{Ct}$ for Correction of Periaxial Malrotation of the Femoral Shaft: A Surface-Matching Approach. Med Phys 2007;34:1380-7. 
9. Scarfe WC, Farman AG, Sukovic P. Clinical Applications of Cone-Beam Computed Tomography in Dental Practice. J Can Dent Assoc 2006;72:7580.

10. Büyük SK, Ramoğlu Sİ. Ortodontik Teşhiste Konik Işınlı Bilgisayarlı Tomografi. Sağ Bil Derg 2011;20:227-34

11. Hidalgo-Rivas JA, Theodorakou C, Carmichael F, Murray B, Payne M, Horner K. Use of Cone Beam Ct in Children and Young People in Three United Kingdom Dental Hospitals. Int J Paediatr Dent 2013(epub ahead of print).

12. Silva MA, Wolf $U$, Heinicke $F$, Bumann A, Visser $H$, Hirsch E. Cone-Beam Computed Tomography for Routine Orthodontic Treatment Planning: A Radiation Dose Evaluation. Am J Orthod Dentofacial Orthop 2008;133:640 e1-5.

13. Mason C, Papadakou P, Roberts GJ. The Radiographic Localization of Impacted Maxillary Canines: A Comparison of Methods. Eur J Orthod 2001;23:25-34.

14. Lai CS, Bornstein MM, Mock L, Heuberger BM, Dietrich $T$, Katsaros C. Impacted Maxillary Canines and Root Resorptions of Neighbouring Teeth: A Radiographic Analysis Using Cone-Beam Computed Tomography. Eur J Orthod 2013;35:529-38.

15. Tantanapornkul W, Okouchi K, Fujiwara Y, Yamashiro M, Maruoka Y, Ohbayashi N, et al. A Comparative Study of Cone-Beam Computed Tomography and Conventional Panoramic Radiography in Assessing the Topographic Relationship between the Mandibular Canal and Impacted Third Molars. Oral Surg Oral Med Oral Pathol Oral Radiol Endod 2007;103:253-9.

16. Bayrak S, Dalci K, Sari S. Case Report: Evaluation of Supernumerary Teeth with Computerized Tomography. Oral Surg Oral Med Oral Pathol Oral Radiol Endod 2005;100:e65-9.

17. Harris D, Buser D, Dula K, Grondahl K, Haris D, Jacobs R, et al. E.A.O. Guidelines Fo the Use of Diagnostic Imaging in Implant Dentistry. A Consensus Workshop Organized by the European Association for Osseointegration in Trinity College Dublin. Clin Oral Implants Res 2002;13:566-70.

18. Widmann G, Bale RJ. Accuracy in Computer-Aided Implant Surgery--a Review. Int J Oral Maxillofac Implants 2006;21:305-13.
19. Lofthag-Hansen S, Grondahl K, Ekestubbe A. ConeBeam Ct for Preoperative Implant Planning in the Posterior Mandible: Visibility of Anatomic Landmarks. Clin Implant Dent Relat Res 2009;11:246-55.

20. Jabero M, Sarment DP. Advanced Surgical Guidance Technology: A Review. Implant Dent 2006;15:135-42.

21. Widmann G, Widmann R, Widmann E, Jaschke W, Bale R. Use of a Surgical Navigation System for CtGuided Template Production. Int J Oral Maxillofac Implants 2007;22:72-8.

22. Sarment DP, Sukovic P, Clinthorne N. Accuracy of Implant Placement with a Stereolithographic Surgical Guide. Int J Oral Maxillofac Implants 2003;18:571-7.

23. Kramer FJ, Baethge C, Swennen G, Rosahl S. Navigated Vs. Conventional Implant Insertion for Maxillary Single Tooth Replacement. Clin Oral Implants Res 2005;16:60-8.

24. Misch CE. Contemporary Implant Dentistry. 3 ed. Los Angeles, California: Mosby Elsevier; 2007.38-9.

25. Ganz SD. Computer-Aided Design/Computer-Aided Manufacturing Applications Using $\mathrm{Ct}$ and Cone Beam Ct Scanning Technology. Dent Clin North Am 2008;52:777-808, vii.

26. White SC PM. Oral Radiology Principles and Interpretation. Edition 6. ed. Los Angeles, California: Mosby Elsevier; 2009.225-37.

27. Kau CH, Bozic M, English J, Lee R, Bussa H, Ellis RK. Cone-Beam Computed Tomography of the Maxillofacial Region--an Update. Int J Med Robot 2009;5:366-80.

28. Guerrero $M E$, Jacobs R, Loubele M, Schutyser F, Suetens $P$, van Steenberghe D. State-of-the-Art on Cone Beam Ct Imaging for Preoperative Planning of Implant Placement. Clin Oral Investig 2006;10:1-7.

29. De Vos W, Casselman J, Swennen GR. Cone-Beam Computerized Tomography (Cbct) Imaging of the Oral and Maxillofacial Region: A Systematic Review of the Literature. Int J Oral Maxillofac Surg 2009;38:609-25.

30. Miller RJ, Bier J. Surgical Navigation in Oral Implantology. Implant Dent 2006;15:41-7. 
31. Kobayashi K, Shimoda S, Nakagawa Y, Yamamoto A. Accuracy in Measurement of Distance Using Limited Cone-Beam Computerized Tomography. Int J Oral Maxillofac Implants 2004;19:228-31.

32. Azari A, Nikzad S. Computer-Assisted Implantology: Historical Background and Potential Outcomes-a Review. Int J Med Robot 2008;4:95104.

33. Kim KD, Ruprecht A, Jeon KJ, Park CS. Personal Computer-Based Three-Dimensional Computed Tomographic Images of the Teeth for Evaluating Supernumerary or Ectopically Impacted Teeth. Angle Orthod 2003;73:614-21.

34. Marmulla R, Wortche R, Muhling J, Hassfeld S. Geometric Accuracy of the Newtom 9000 Cone Beam Ct. Dentomaxillofac Radiol 2005;34:28-31.

35. Bender IB. Factors Influencing the Radiographic Appearance of Bony Lesions. J Endod 1997;23:514.

36. Scarfe WC, Farman AG. What Is Cone-Beam Ct and How Does It Work? Dent Clin North Am 2008;52:707-30.

37. Kau CH, Richmond S, Palomo JM, Hans MG. ThreeDimensional Cone Beam Computerized Tomography in Orthodontics. J Orthod 2005;32:282-93.

38. Sümbüllü MA, Çakur B, Harorlı A. Antral Retansiyon Kistinin Radyolojik Tespiti; Dental Volümetrik Tomografi Ile Waters Pozisyonunda Çekilen Paranazal Sinüs Radyogramın Karşılaştırıması. Atatürk Üniv. Diş Hek. Fak. Derg. 2011;21:63-7.

39. Önal N. Paranasal Sinüs Inflamatuar Hastalıklarında Bilgisayarlı Tomografi Ve Waters Grafisinin Karşılaştırılması. [Uzmanlık tezi ]. İstanbul; 2006.

40. Rigolone M, Pasqualini D, Bianchi L, Berutti E, Bianchi SD. Vestibular Surgical Access to the Palatine Root of the Superior First Molar: "LowDose Cone-Beam" Ct Analysis of the Pathway and Its Anatomic Variations. J Endod 2003;29:773-5.

\section{Yazışma Adresi:}

Yrd. Doç. Dr. Elif Tarım Ertaş, İzmir Kâtip Çelebi Üniversitesi, Diş Hekimliği Fakültesi, Ağız Diş Ve Çene Radyolojisi Anabilim Dalı, 35640, İzmir TÜRKİYE.

Tel: +902323254040

Fax: +90 2323252535

E-mail: dteliftarim@yahoo.com 